\title{
Demographic Transition in Finland and in Hungary: A Comparative Study
}

\section{LÁSZLÓ HABLICSEK}

\author{
Deputy Director \\ Demographic Research Institute \\ Central Statistical Office in Hungary
}

\section{Introduction}

A comparison between Finland and Hungary regarding their long-term population development promised to be interesting for several reasons. The Finnish and the Hungarian languages belong to the same, rather peculiar family of languages in Europe. In the course of their history both countries have been exposed to strong eastern and western influences. As a consequence of their respective geographic situations they were constantly forced to balance between countries of different cultures and levels of development. It seems to be important that the distribution of outside influence over time was different during the last one and a half centuries. Until the end of World War I Finland was, for a long time, a Grand Duchy of the Russian Empire. In this period Hungary belonged to the Habsburg Empire and later it was an associate state of the Austro-Hungarian Monarchy. After World War I both countries became independent. Hungary had lost two-thirds of its area and one-third of its population. During the last four decades Hungary belonged to the Eastern European sphere of influence of the Soviet Union, while Finland has been fulfilling, step by step, the northern model of the market economy and welfare state.

Naturally, one cannot know how far these characteristics have been relevant from the point of view of population development. However, one can assume that Finland and Hungary have special similarities and differences within the European demographic transition. It is justified to subject this assumption to thorough study. Namely, most papers dealing with the European demographic transition classify the two countries into different groups. In more detailed studies a somewhat different picture is given. In his well-known monograph Lutz (1987) has proved that the transition patterns of Finnish nuptiality and fertility were close to the western type. Lindgren (1990) finds it worthy of attention that in Finland the breakthrough of industrialization similarly to some Eastern European countries - took place relatively late, which lends to Finland »a unique position regarding European demographic transition». According to the early fertility decline (Demeny 1968) and other peculiarities the Hungarian population development is called »in-between» in certain studies.

The practical analysis of the demographic transition was based, for a long time, on crude vital statistical rates and some basic population census data. Regarding its criticism, see Valkovics, 1982. From a methodological point of view the Princeton study represented a big step forward. The Princeton indexes (Coale 1969) are standardized indicators suitable for use in comparisons both over time and space.

Today even more detailed information than that is available. In the form of reconstructed data and additional estimates the accessories of modern demographic anal- 
ysis - life tables, age-specific fertility rates, measurements of reproduction etc. exist - for the whole period of demographic transition. The characteristics of birth cohorts can also be studied. With such a widening of the sources, on the basis of new methods, a large-scale project on the European demographic transition could take place in the 1990s.

Hungary and Finland belong to those countries which are in a good position regarding the above sources of data. Owing to the excellent population registration introduced after the Swedish pattern, mortality and fertility in Finland can be analyzed retrospectively for two and a half centuries. In Hungary, it is the systematic population censuses recurring every decade from 1869 on which provide a good basis for the production or estimation of similar information.

The purpose of this study is to compare the demographic transition in the two countries during the period 1881-1986. The analysis centers on the classical twofactor model: the development of fertility and mortality, changes in the size and in the age structure of the population by calendar periods and by birth cohorts. As a supplement, some population scenarios, calculated for the period between 1991-2041, are presented. They investigate the impact of the different levels of fertility and mortality and of the age structure observed in the mid-1980s.

\section{Data and methods}

The basis of the study is the following stock of data, equally detailed with regard to both countries:

- Population figures by sex and by five-year age groups from 1881 to 1986 for every five years. Those aged 85 years and over have been summed up in an open age group.

- Fertility rates by five-year age groups of mothers as averages of five calendar years from $1881-1885$ to $1981-1985$.

- Transversal life tables by sex and five-year age groups as averages of five calendar years from $1881-1885$ to $1981-1985$.

The fertility rates of Finland are from Lutz's above-mentioned monograph (Lutz 1987), while the Finnish life tables and corrected population figures have been taken from the work by Kolari (Kolari 1980).

The data and estimations for Hungary rely upon four sources: on the population figures and other information published in the Demographic Yearbooks of the Central Statistical Office in Hungary (HCSO), on Pallós's and Józan's life tables (Pallós 1972 and, respectively, Józan 1984) and on Kamarás's excellent compilation regarding the nuptiality and fertility of birth cohorts (Kamarás 1981). From the sources, the author - following Lutz's way of "putting together all pieces of information» - has produced, by iterative estimates, the data collection of a system similar to that of Finland (Hablicsek 1991(a)).

From the stocks ordered by calendar periods and age groups, so-called quasi-cohort estimates could be obtained by diagonal selections (Schwarz 1986). On this basis, an estimated stock of data which also includes the population figures, fertility rates and life tables - can be produced also with regard to the birth cohorts. In the case of cohorts whose life history had not ended by 1986, fertility and mortality observed in the period between 1981-1985 was added. It is to be noted that there are some inconsistencies between the stocks of data, for example, the calculation of fertility rates is different in the Hungarian and Finnish materials. 
In the study mostly indicators not dependent on the age structure were placed in the center of the analysis. The total fertility rate (TFR) represents the average number of children delivered by one woman (the sum of fertility rates by age groups multiplied by five). Within that the gross reproduction rate (GRR) refers only to girls (TFR multiplied by the proportion of girls within all births). The timing of fertility is equal to the percentage distribution of the rates by age groups. Survival probability from birth until a given age group is one-fifth of $\mathrm{L}(\mathrm{x}, \mathrm{x}+4)$ in the abridged life table with a unit root. The stationary population in a given age group is the product of the number of births and the probability of survival in a given calendar period. The size of the stationary population is the sum of these population figures by age groups.

The net reproduction rate (NRR) represents the average number of girls expected to be delivered by one newborn girl. It can be regarded also both as the rate of increase between two generations as well the quotient of the number of births of two generations. NRR was calculated by summarizing the products of the probabilities of survival and fertility rates with regard to girls (the net fertility rates). The sum here - as also in the case of TFR - has to be multiplied by five.

The dependency rate (DEPR) is, as a rule, the population aged $0-14$ years and, respectively, 65 years and more over the population aged $15-64$ years. Every indicator mentioned above can be calculated adopting both the transversal and the longitudinal approaches, as well as for actual and stationary populations.

As a supplement to the study, combining two mortality and three fertility assumptions, six population scenarios have been prepared by the cohort component method, by five-year age groups and by five-year steps from 1991 to 2041 . The $1991 \mathrm{popu}-$ lation was estimated on the basis of the 1986 population using the benchmark scenario. Life expectancies at birth were taken to be 70 and 80 years, respectively, and total fertility rates to be $1.5,1.8$ and 2.1 . These levels of fertility are constant between 1991 and 2040, while life expectancy at birth changes. Starting from the values for $1981-1985$ it reaches, linearly, 70 and 80 years, respectively, by 2030 . For lengths of life perspective death rates were determined by using Brass's method (For more details, see Scenarios).

In presenting the data and calculations, preference was given to figures. The purpose of this is to somewhat stress the preliminary and estimated nature of Hungary's data, especially with regard to the period before 1920 .

\section{The transition of mortality}

In 1881-1885 life expectancy at birth for both sexes may have been 41 years in Finland and 31 years in the present-day area of Hungary. The significant difference of 10 years can hardly be explained by a possible shift of time between the beginnings of the mortality decline. In Finland the average span of life was, from 1750 to 1880 , about 35 years and the increase can be calculated from here (CSO 1987). Klinger (1980) also puts the beginning of the transition of mortality in Hungary in the 1880 s. It can well be assumed that a difference in mortality between the two countries existed throughout the whole 19th century. It can be partly attributed to the higher intensity of epidemics in Hungary. According to one estimate (Hablicsek 1991(b)), in the present-day area of Hungary, in the 1820s, the mean length of life was 28.5 years, though in that decade »only" four minor epidemics - two of influenza, one of smallpox and one of malaria - took place. 
Figure 1. Life expectancy at birth in calendar periods, Finland and Hungary, 1881-1985.

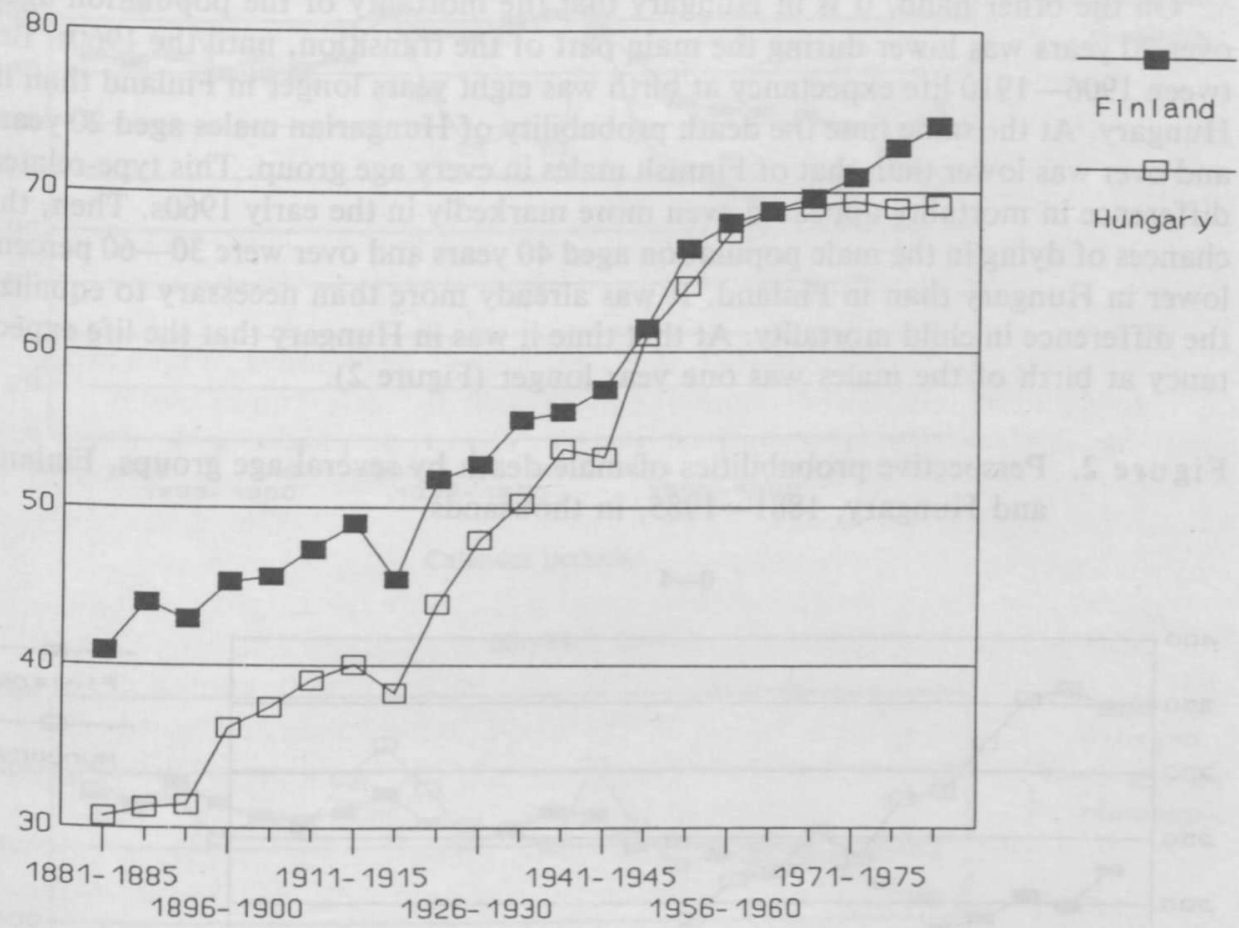

Calendar periods

By the mid-1960s, in the course of the transition, the initial great difference had gradually disappeared. The difference in the life expectancies of the newborns was in 1901-1905, in 1931-1935 and in 1951-1955 still eight, five and already only two and a half years, respectively. On the average, in 1961-1965 a newborn could expect to have an average of 69 years life span in both countries (Figure 1).

One possible reason why the duration of life in the two countries had come closer to each other by the 1960 s is rather obvious. According to the model life tables of Coale and Demeny (1966) Finland and Hungary belonged to the northern and, respectively, to the eastern type of European mortality. On an identical mortality level, the difference between the two types is that in the northern type the mortality of infants and children is lower than in the eastern type. In the case of the adult population the reverse is true: the eastern mortality is lower than the northern.

The general characteristic of the mortality transition is that the decrease takes place, first, in the younger age groups, predominantly in the mortality rates of infants and children. This is followed, later, by the increase in the life chances of the middle-aged. Beginning with the mid-1970s, in the most recent phase, the point of gravity of the decline has moved over to the elderly.

Between 1881 - 1885, in Finland the perspective probability of death of boys aged $0-4$ years was 23 percent, while the corresponding value in the present-day area of Hungary may have been 35 percent. The initial difference, 1.5 times greater in Hungary, has even increased in the course of the transition. Between 1961-1965 the values were 23 and 50 per thousand, respectively. At the same time the ever falling levels of infant and child mortality had a continuously declining impact on the increase 
in average life expectancy at birth. This fact alone resulted in a considerable decrease in the differences between life spans.

On the other hand, it is in Hungary that the mortality of the population aged over 20 years was lower during the main part of the transition, until the $1960 \mathrm{~s}$. Between 1906-1910 life expectancy at birth was eight years longer in Finland than in Hungary. At the same time the death probability of Hungarian males aged 20 years and over was lower than that of Finnish males in every age group. This type-related difference in mortality appeared even more markedly in the early $1960 \mathrm{~s}$. Then, the chances of dying in the male population aged 40 years and over were $30-60$ percent lower in Hungary than in Finland. It was already more than necessary to equalize the difference in child mortality. At that time it was in Hungary that the life expectancy at birth of the males was one year longer (Figure 2).

Figure 2. Perspective probabilities of male death by several age groups, Finland and Hungary, 1881-1985, in thousands.

$$
0-4
$$

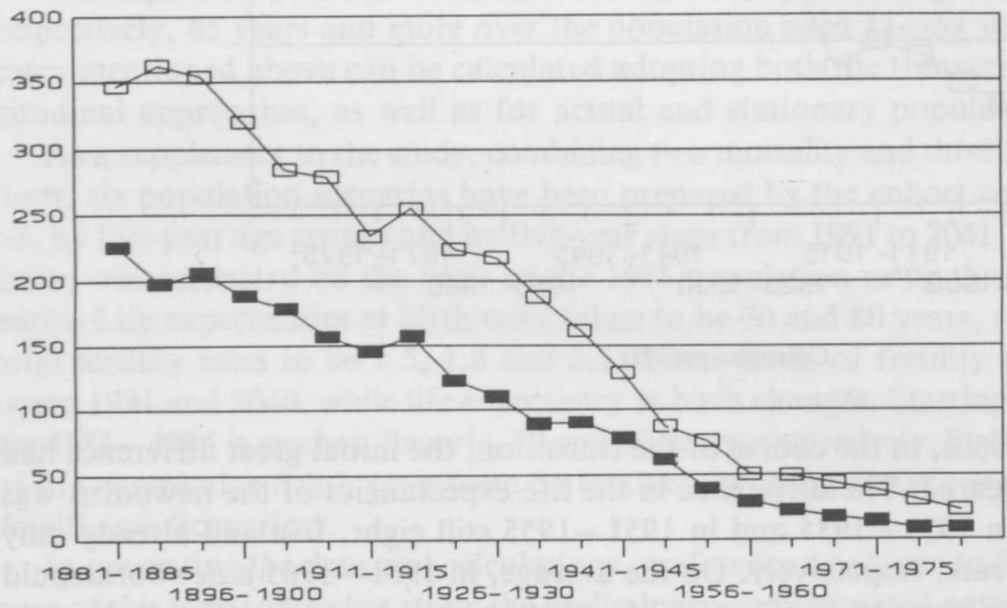

Calendar periods

$40-44$
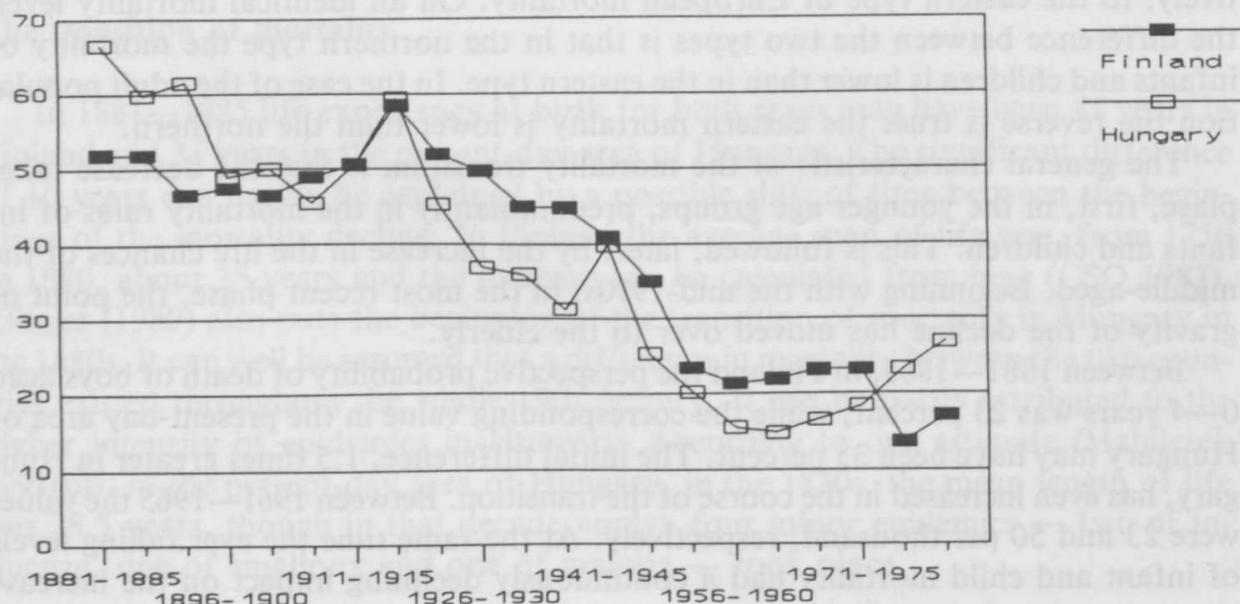

Calendar periods 

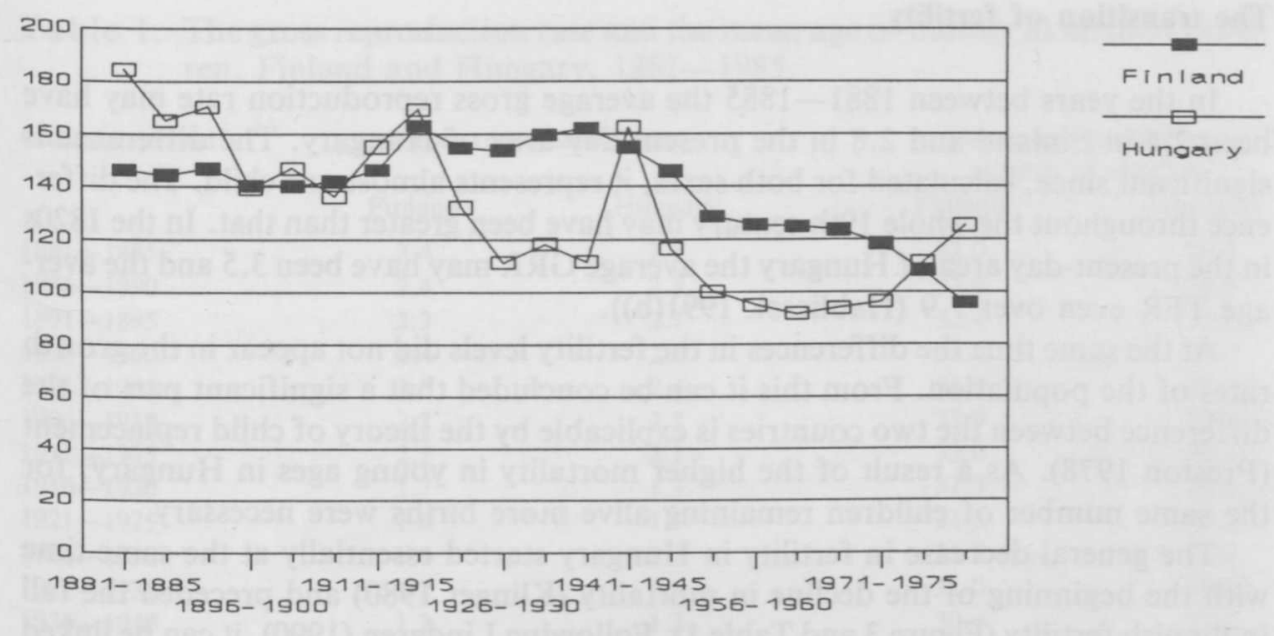

Calendar periods

$$
80-84
$$
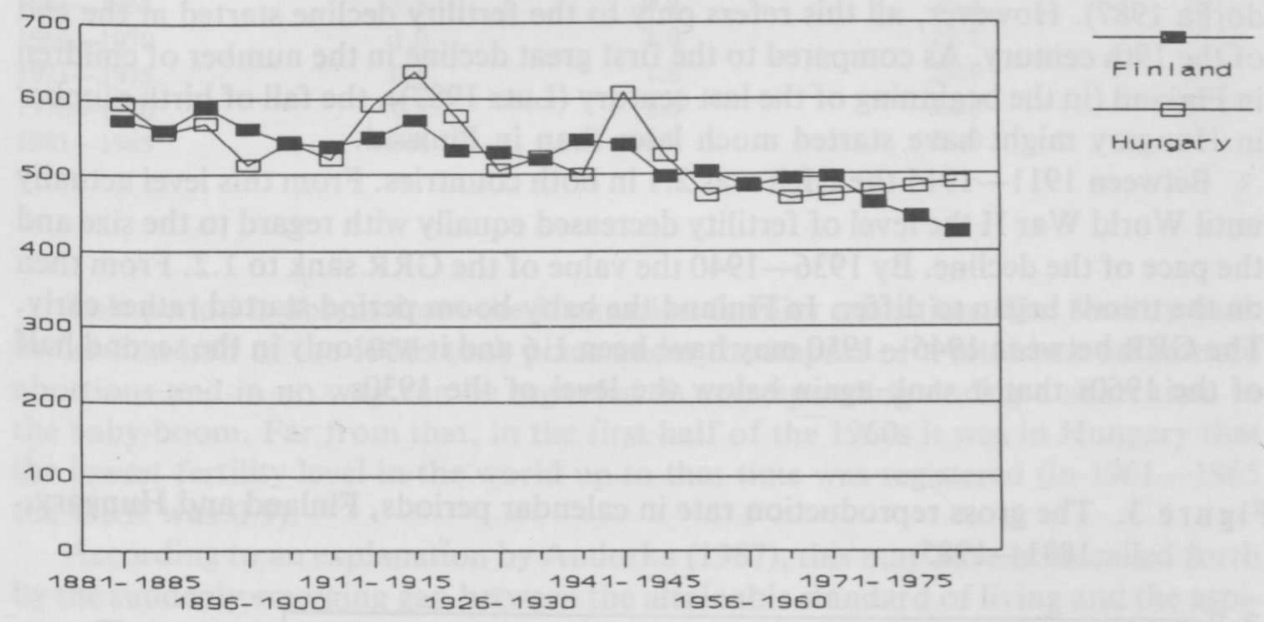

Calendar periods

Since the early 1970 s, regarding the mortality differences between the two countries, a new phase has come into being. In Finland, the span of life increased by five years until 1986 while in Hungary it remained on the same level it had been twenty years earlier. In the new phase, in Finland a general decrease in mortality, covering almost all age groups and especially significant in the elderly age groups, took place. In this period, in Hungary, the risk of dying increased in the case of the total population aged 25 years and over. By 1981-1985, the mortality rates of males, in some age groups, doubled and became higher than the respective Finnish rates had been twenty years earlier. It seems that the two countries have "exchanged» their types of mortality. It can be assumed, following a study of Valkonen (1984) on Finnish mortality, that it is the mass smoking of bad-quality cigarettes, the unbridled consumption of hard liquors, the habit of eating foods abundant in fats and a host of similar causes may have led in Hungary to a stagnation and, respectively, increase in mortality, unprecedented in its duration in the demographic transition. 


\section{The transition of fertility}

In the years between $1881-1885$ the average gross reproduction rate may have been 2.4 in Finland and 2.8 in the present-day area of Hungary. The difference is significant since, calculated for both sexes, it represents almost one child. The difference throughout the whole 19th century may have been greater than that. In the $1820 \mathrm{~s}$ in the present-day area of Hungary the average GRR may have been 3.5 and the average TFR even over 7.9 (Hablicsek 1991(b)).

At the same time the differences in the fertility levels did not appear in the growth rates of the population. From this it can be concluded that a significant part of the difference between the two countries is explicable by the theory of child replacement (Preston 1978). As a result of the higher mortality in young ages in Hungary, for the same number of children remaining alive more births were necessary.

The general decrease in fertility in Hungary started essentially at the same time with the beginning of the decline in mortality (Klinger 1980) and preceded the fall in Finnish fertility (Figure 3 and Table 1). Following Lindgren (1990), it can be linked up with a possible difference over time regarding the breakthrough in industrialization. Besides, a peculiar feature of the Hungarian demographic transition is that the fall in the number of children among the peasantry happened relatively early (Andorka 1987). However, all this refers only to the fertility decline started at the end of the 19th century. As compared to the first great decline in the number of children in Finland (in the beginning of the last century (Lutz 1987)), the fall of birth number in Hungary might have started much later than in Finland.

Between 1911 - 1915 the GRR was 2.1 in both countries. From this level actually until World War II the level of fertility decreased equally with regard to the size and the pace of the decline. By 1936-1940 the value of the GRR sank to 1.2. From then on the trends began to differ. In Finland the baby-boom period started rather early. The GRR between 1946 - 1950 may have been 1.6 and it was only in the second half of the 1960 s that it sank again below the level of the 1930 s.

Figure 3. The gross reproduction rate in calendar periods, Finland and Hungary, $1881-1985$.

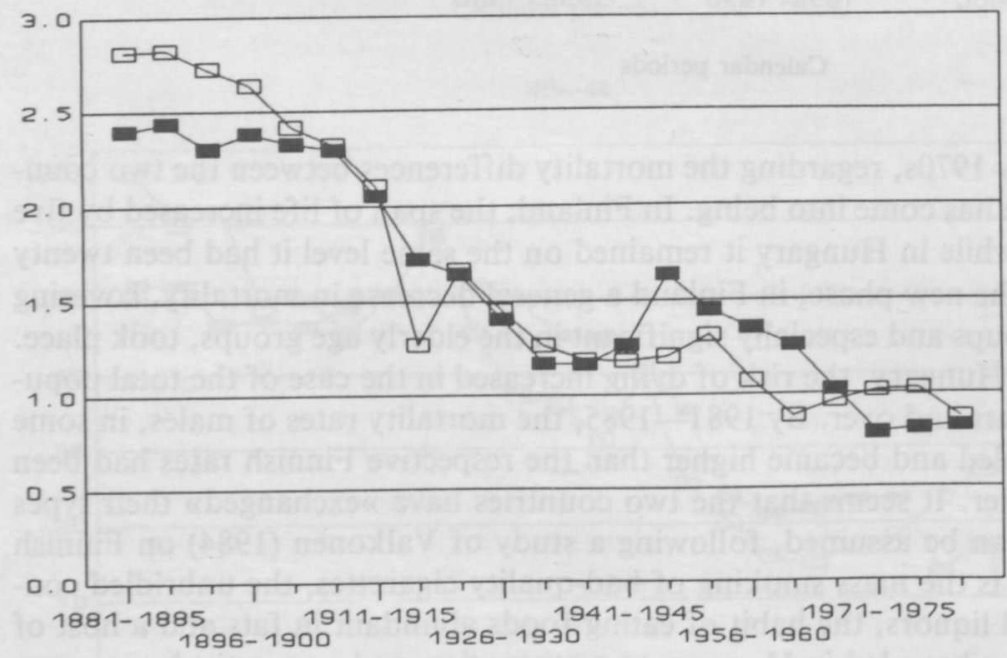


Table 1. The gross reproduction rate and the mean age of mother at birth of children, Finland and Hungary, 1881-1985.

Calendar period

$\begin{array}{cc} & \text { Finland } \\ 1881-1885 & 2.4 \\ 1886-1890 & 2.4 \\ 1891-1895 & 2.3 \\ 1896-1900 & 2.4 \\ 1901-1905 & 2.3 \\ 1906-1910 & 2.3 \\ 1911-1915 & 2.1 \\ 1916-1920 & 1.7 \\ 1921-1925 & 1.6 \\ 1926-1930 & 1.4 \\ 1931-1935 & 1.2 \\ 1936-1940 & 1.2 \\ 1941-1945 & 1.3 \\ 1946-1950 & 1.6 \\ 1951-1955 & 1.4 \\ 1956-1960 & 1.4 \\ 1961-1965 & 1.3 \\ 1966-1970 & 1.0 \\ 1971-1975 & 0.8 \\ 1976-1980 & 0.8 \\ 1981-1985 & 0.8\end{array}$

Gross reproduction rate

$\begin{array}{lc}\text { Finland } & \text { Hungary } \\ 2.4 & 2.8 \\ 2.4 & 2.8 \\ 2.3 & 2.7 \\ 2.4 & 2.6 \\ 2.3 & 2.4 \\ 2.3 & 2.3 \\ 2.1 & 2.1 \\ 1.7 & 1.3 \\ 1.6 & 1.7 \\ 1.4 & 1.5 \\ 1.2 & 1.3 \\ 1.2 & 1.2 \\ 1.3 & 1.2 \\ 1.6 & 1.2 \\ 1.4 & 1.3 \\ 1.4 & 1.1 \\ 1.3 & 0.9 \\ 1.0 & 1.0 \\ 0.8 & 1.0 \\ 0.8 & 1.0 \\ 0.8 & 0.9\end{array}$

Mean age of mother at birth of children Finland Hungary

$\begin{array}{ll}32.0 & 29.9\end{array}$

$\begin{array}{ll}32.0 & 29.9\end{array}$

$\begin{array}{ll}32.0 & 29.8\end{array}$

$\begin{array}{ll}31.9 & 29.7\end{array}$

$\begin{array}{ll}31.9 & 29.7\end{array}$

$31.9 \quad 29.4$

$32.0 \quad 30.1$

$\begin{array}{ll}31.9 & 28.6\end{array}$

$\begin{array}{ll}31.5 & 29.3\end{array}$

$31.3 \quad 29.0$

$\begin{array}{ll}31.0 & 28.8\end{array}$

$30.4 \quad 28.4$

$30.6 \quad 28.3$

$\begin{array}{ll}29.6 & 27.7\end{array}$

$29.2 \quad 27.3$

$\begin{array}{ll}28.6 & 26.7\end{array}$

$28.2 \quad 26.0$

$\begin{array}{ll}27.5 & 25.6\end{array}$

$26.9 \quad 25.3$

$27.5 \quad 25.1$

$28.0 \quad 25.1$

This period is absent from the Hungarian fertility transition. The fertility peak in the first half of the 1950s took place under the impact of a total ban on induced abortions and in no way can be regarded as corresponding during a short time to the baby-boom. Far from that, in the first half of the 1960s it was in Hungary that the lowest fertility level in the world up to that time was registered (in 1961-1965 the GRR was 0.9).

According to an explanation by Andorka (1987), this may have been called forth by the suddenly emerging gap between the attainable standard of living and the aspirations, i.e. by an Easterlin-type of influence. The shortage which constantly reproduces itself, characteristic of the Eastern European so-called socialist systems, and the desires entertained and the means used and permitted to reduce it in Hungary may have had a great impact also on the later development of Hungarian fertility.

In the $1970 \mathrm{~s}$, in the two countries the number of children changed by reversed curves. In Finland, the »large age groups» having entered adulthood, fertility reached its bottom (the GRR level was 0.8), then it rose somewhat until 1986. In Hungary, after the population policy program and the introduction of widescale benefits as inducements for having a higher number of children, the calendar fertility level increased (in the 1970s the average GRR was 1.0 ). However, in the early 1980s the level of the GRR fell back. Recently the fertility in the two countries is again approximately identical (Figure 3 and Table 1).

The development of the level of fertility of the birth cohorts (Figure 4) shows even more markedly that in the two countries the first phase of the decrease (the cohorts born between 1866-1910) was essentially the same both with regard to its size and its pace. The impact of the peak of the baby-boom in Finland and its absence in Hungary (the cohorts born between 1911 and 1945) are sharply visible. Sub- 
Figure 4. The gross reproduction rate in the birth cohorts, Finland and Hungary, 1866-1970.
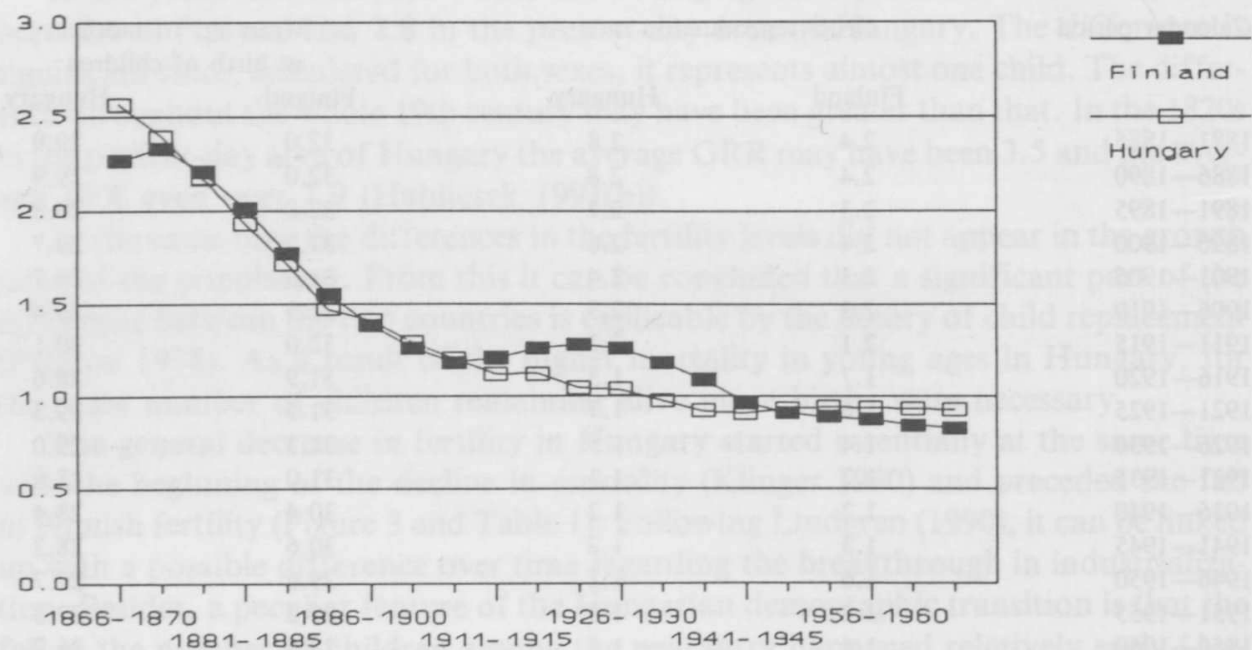

Period the cohort was born

sequently, the number of children of those Hungarian cohorts, whose most active child-bearing period fell in the 1970 s, is somewhat higher. The values of the last points in Figure 4 refer to cohorts whose fertility history is not completed. The final value depends on the fertility of the 1990s. As far as the future is concerned, by the 1980s fertility in the two countries was nearly in the same starting position.

The differences with regard to the timing of fertility were, in the case of Finland and Hungary, insensitive to the changes in the number of children. In Finland, the average child-bearing age of mothers was always $2-3$ years higher than in Hungary, even when the fertility levels were different (Table 1). The difference between the most probable child-bearing ages was the same. Finland's fertility followed the western pattern rather closely, while Hungary went unequivocally after the eastern one. It would seem that the different patterns had no direct connection with the level of the number of children. In the next part, however, it will be seen that with regard to net reproduction the Finnish pattern was more productive than the Hungarian.

\section{Reproduction, population growth}

The reproduction of the population can be discussed in many ways. Since Lotka (1907) the net reproduction rate has become a concept in demography. In fact, it measures the reproduction of the number of births. It expresses the number of daughters a newborn girl will give birth to in the course of her life. In stable population theory this indicator is directly connected with population growth. The intrinsic growth rate (IGR) is the growth in NRR for one year between generations. However, real populations are not stable populations, and especially not in the course of demographic transition. Here, one has to reckon with at least three factors concerning the growth of the population.

The first is the age structure of the population at the beginning of the transition. It is then very young and, consequently, ensures the growth in the size of the popula- 
tion for a long time, even with a decrease in the number of children. The second is the decrease in mortality during the period of transition and even beyond. During the transition the number of children of subsequent generations declines. However, their chances of survival grow. This, considering the number of generations at adult ages, may equalize the lower number of births. Finally, external migration may also play a significant role, especially in some prominent periods and in long-term reverberations afterwards.

Three indicators are studied: the net reproduction rate, the size of the stationary population and the population growth since the beginning of the transition. The size of the stationary population measures the total number of the years of life to be lived by the members of the cohort. This product of birth number and life expectancy at birth is from Henry (1965) and indicates the extent to which the decrease in the number of births is counterbalanced by the increase in the life span and vice versa. The actual population growth, insofar as it refers to the whole duration of the transition, was introduced by Chesnais (1983). He divided the population number at the end of the transition by the population number at its beginning and named the multiplicator of the transition. In this study, this quotient was calculated also with regard to intermediate points of time dividing the population number at the respective points of time by the population number in 1881 .

In the course of the demographic transition the net reproduction rate in Finland was significantly higher than in Hungary. Due to lower infant and child mortality it was so even at the beginning of the transition, when the Finnish fertility level was much lower than the Hungarian. Later, in the baby-boom period, the Finnish NRR surpassed by far the corresponding Hungarian value, also because of the higher Finnish fertility. The development of the net reproduction rate of the birth cohorts (Figure 5) in Hungary is probably unique in Europe. There is hardly any other country where, in the middle phase of the transition, the NRR estimated for the female cohorts does not attain even 0.8. In Hungary women born between 1901-1940 gave birth to $25-30$ percent fewer girls than their own number of births. The average child-bearing age of these cohorts coincided with the years between 1930 and 1965 .

Figure 5. The net reproduction rate in the birth cohorts, Finland and Hungary, 1866-1970.
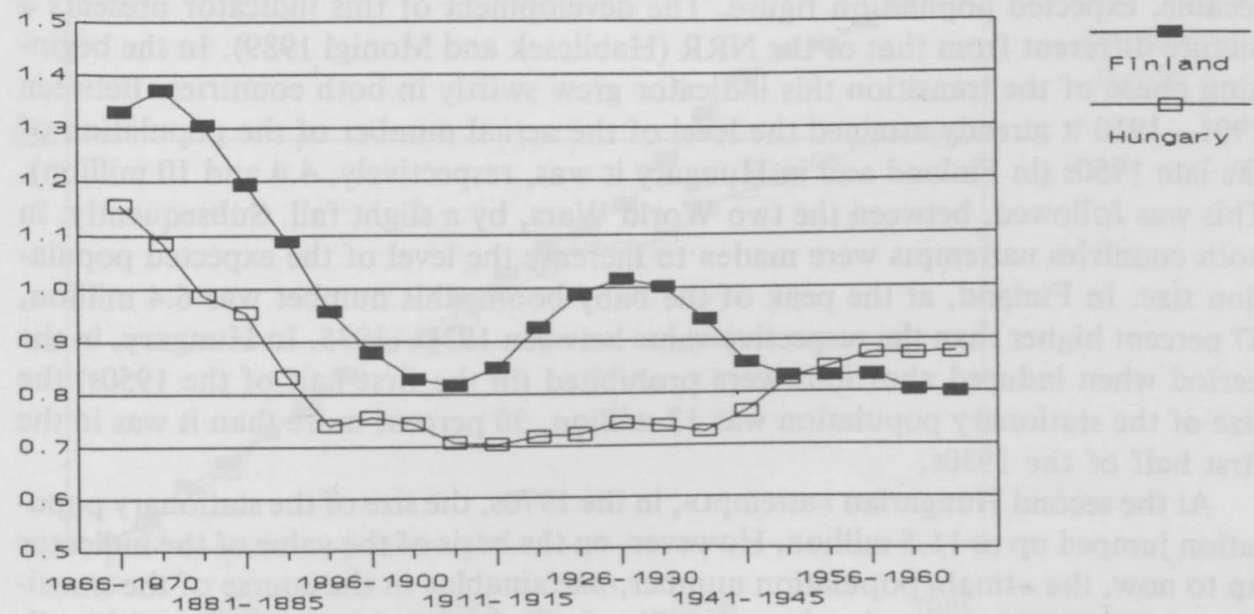

Period the cohort was born 
Figure 6. Size of stationary population in calendar periods, Finland and Hungary, $1881-1985$, in millions.
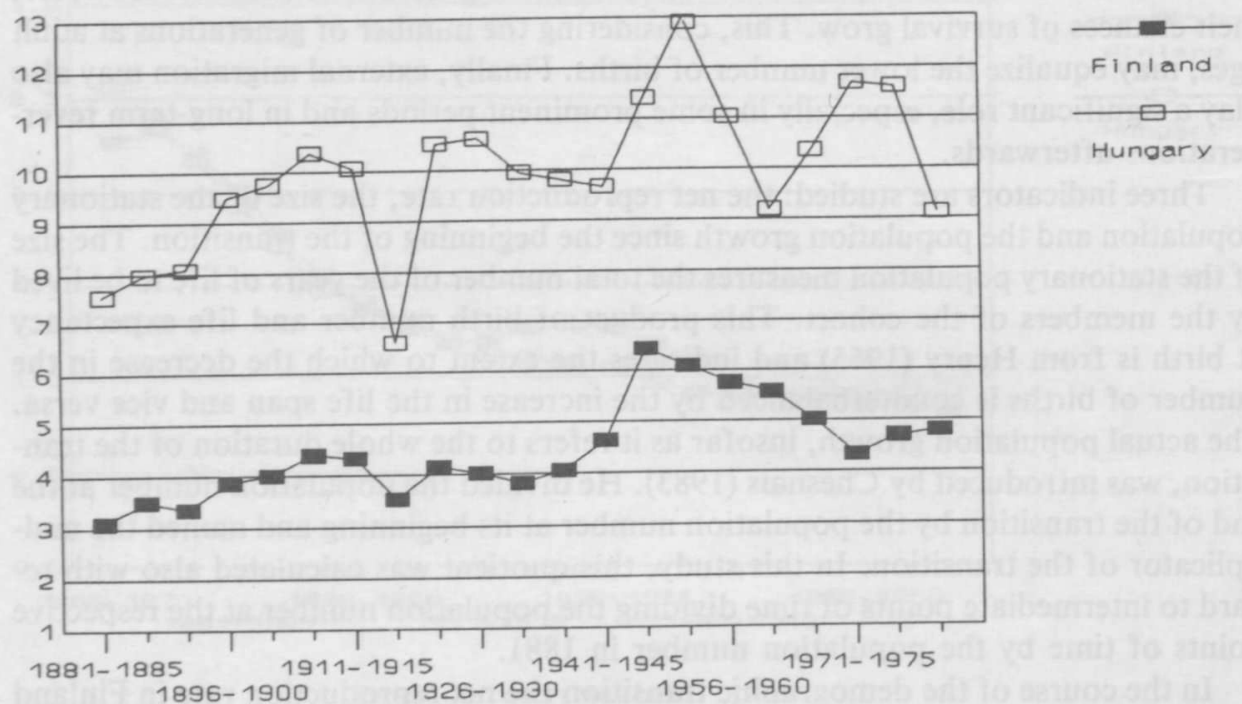

Calendar periods

The NRR in Finland in the female cohort born between 1871-1875 approached 1.4 , but in the case of the female cohort born between 1906-1910, it was already only 0.8 . In the subsequent cohorts, under the impact of the baby-boom period, the NRR rose. In the case of those born between 1926-1935 it again reached replacement level. The NRR of the female cohort born between 1941-1945 may have been nearly the same in the two countries. Later, presumably under the impact of the population policy pursued in the 1970s, the Hungarian NRR was slightly over the Finnish value. The last points of Figure 5 are already not real and so it is not known whether this is a lasting difference or a provisional one.

The size of the stationary population (Figure 6) also represents some sort of foreseeable, expected population figure. The development of this indicator presents a picture different from that of the NRR (Hablicsek and Monigl 1989). In the beginning phase of the transition this indicator grew swiftly in both countries. Between $1901-1910$ it already attained the level of the actual number of the population of the late 1950s (in Finland and in Hungary it was, respectively, 4.4 and 10 million). This was followed, between the two World Wars, by a slight fall. Subsequently, in both countries «attempts were made» to increase the level of the expected population size. In Finland, at the peak of the baby-boom, this number was 6.4 million, 67 percent higher than the respective value between 1931-1935. In Hungary, in the period when induced abortions were prohibited (in the first half of the 1950s) the size of the stationary population was 13 million, 30 percent more than it was in the first half of the 1930s.

At the second Hungarian »attempt», in the 1970s, the size of the stationary population jumped up to 11.5 million. However, on the basis of the value of the indicator up to now, the »final» population number, nattainable» in the course of the transition, may be estimated to be about 5 million in Finland and between 10 and 11 million in Hungary. This is not much more than what was already »foreseeable» around 
1910. And this can become reality only if the changes in the number of births and in the life span will further equalize each other also in the future, as an average of longer periods.

The ratio of the actual number of the population to the population in 1881 shows a population increase since the beginning of the transition. Until 1916 the values were nearly identical in both countries. Since during World War I in Hungary the number of births was extremely low, a difference in the indicator appeared here. However, the population growth of the two countries then continued to be rather similar until 1941 (Figure 7).

After 1946 the development of the population growth calculated from the beginning of the transition was different in the two countries. In Finland, the nearly linear trend continued, while in Hungary the increase slowed down and from 1981 to 1986 even went into a decrease. In 1986, in Finland there were 2.4 times more people and in the present-day area of Hungary 2.0 times more people than in 1881 . Both values are lower than average in Europe. The Hungarian value is one of the smallest.

Consequently, in the period of demographic transition, population reproduction in Hungary was, in all aspects, lower than in Finland. It is rather difficult to clarify the reasons underlying this fact. Various indicators offer different possibilities for explanation. However, it seems that the big decline in fertility until 1930, then the subsequent extraordinarily low reproduction of the number of births between 1931 -1965 , the stagnation and the decrease in the life span after 1965 and the population decrease which started as one of the first in Europe since the early 1980s all fit into the same line. The conditions of population reproduction in Hungary - perhaps related to the well-known historical peculiarities - have been worse than the European average throughout the whole period of the transition and especially since the first third of the 20th century.

Figure 7. Growth of population since 1881 by calendar years, Finland and Hungary, 1881-1985 (in percentage).

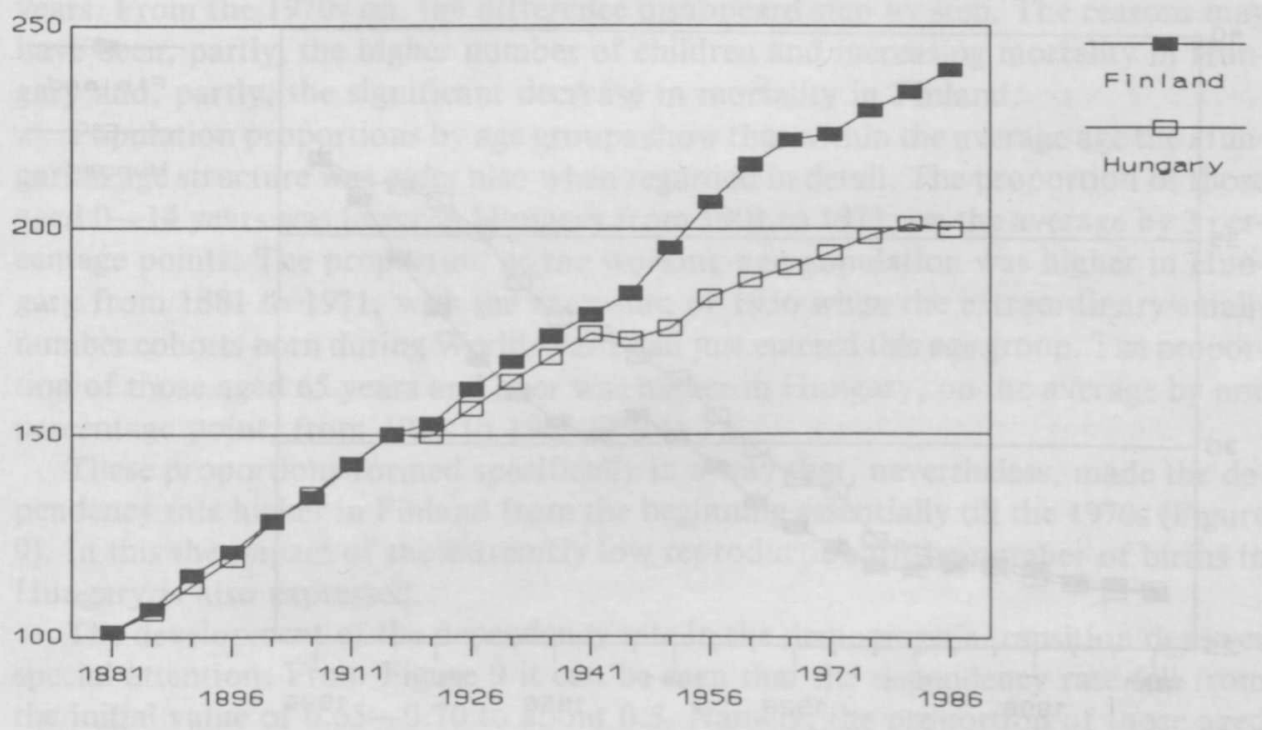

Calendar years 


\section{The age structure of the population}

One of the most important consequences of the transition of fertility and mortality are the changes in the age structure of the population, the process of aging. Studies dealing with the causes of aging point out the impact of fertility, noting that also mortality and, to a lesser extent, out-migration have had an impact on the age structure.

On the other hand, one can point out the impact of the decline in mortality. The calendar year population is composed from different birth-year generations. An age group of the population - disregarding out-migration - is the product of the number of births of the respective cohort and the latter's probability of survival. Here, mortality may have an impact equal to that of fertility. And if two cohorts are compared from the point of view of the proportions of the years their members spend in various age groups, the differences can already obviously be accounted for by mortality differentials.

In the beginning of the demographic transition the age structure of the Finnish and Hungarian populations was nearly the same. In 1881, the proportions of those aged $0-14,15-64$ and $65+$ years may have been, respectively, 35-36, $60-61$ and 4 percent. The average age of the population may be estimated to have been 26.4 years in Finland and 26.4 years in Hungary. 105 years later, in 1986, almost the same similarity can be witnessed. The average age was 36.5 years in Finland and 36.6 years in Hungary. Behind this average, the proportions of the younger age groups in Finland were somewhat lower than in Hungary and those of the elderly somewhat higher than in Hungary (Figure 8).

On the other hand, between the two extreme points of time essential differences between the two countries are visible. In a great part of the demographic transition the age structure was significantly older in Hungary than in Finland.

Figure 8. Average age of population in calendar years, Finland and Hungary, $1881-1986$.

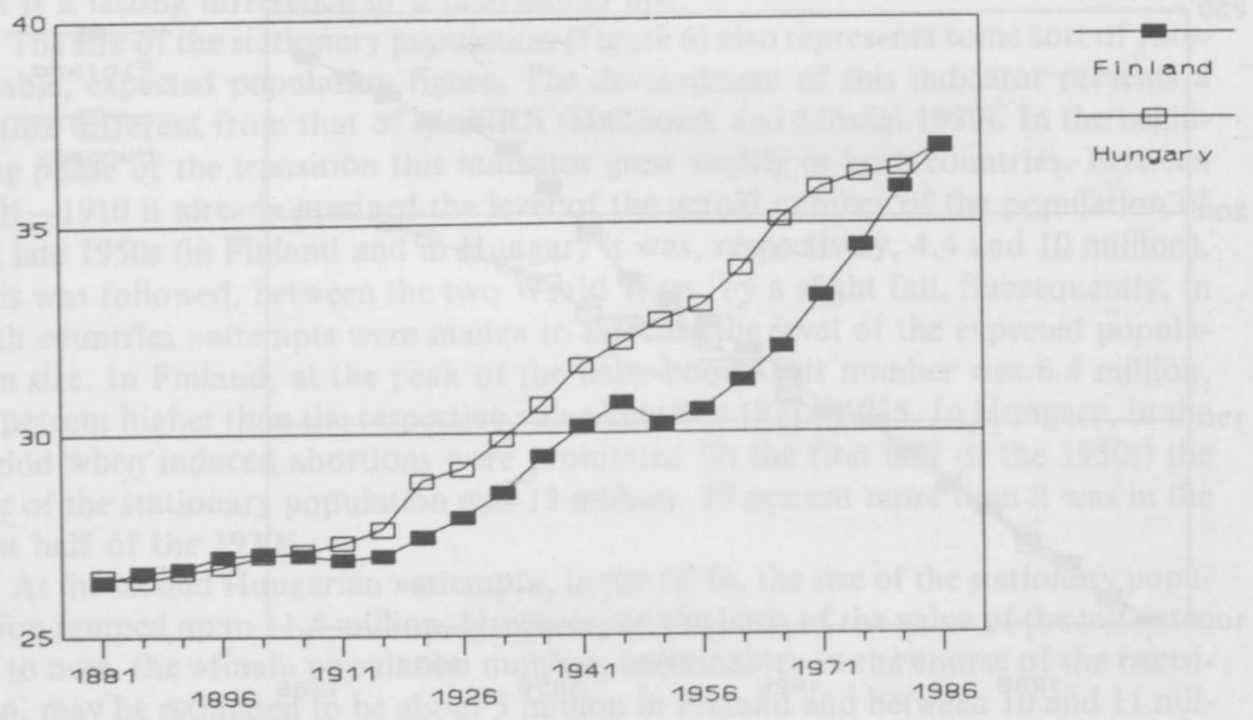

Calendar years 
Table 2. Population distribution by main age groups in calendar years, Finland and Hungary, 1881-1986, both sexes.

Calendar years

\begin{tabular}{|c|c|c|c|c|c|c|}
\hline & & $\begin{array}{l}\text { Finland } \\
15-64\end{array}$ & $65+$ & $0-14$ & $\begin{array}{c}\text { Hungary } \\
15-64\end{array}$ & $65+$ \\
\hline 1881 & 35.5 & 60.5 & 4.0 & 35.2 & 61.2 & 3.6 \\
\hline 1886 & 36.0 & 59.5 & 4.4 & 36.0 & 60.0 & 4.1 \\
\hline 1891 & 35.8 & 59.4 & 4.8 & 36.2 & 59.6 & 4.2 \\
\hline 1896 & 35.2 & 59.8 & 5.1 & 35.8 & 59.9 & 4.2 \\
\hline 1901 & 35.0 & 59.9 & 5.1 & 34.9 & 60.7 & 4.4 \\
\hline 1906 & 35.4 & 59.3 & 5.3 & 35.2 & 60.0 & 4.8 \\
\hline 1911 & 36.2 & 58.2 & 5.6 & 34.8 & 60.3 & 5.0 \\
\hline 1916 & 35.8 & 58.5 & 5.7 & 34.0 & 60.7 & 5.2 \\
\hline 1921 & 34.1 & 60.1 & 5.8 & 30.6 & 63.8 & 5.6 \\
\hline 1926 & 31.7 & 62.5 & 5.8 & 29.0 & 65.1 & 5.9 \\
\hline 1931 & 29.7 & 64.4 & 5.9 & 27.5 & 66.1 & 6.3 \\
\hline 1936 & 28.4 & 65.8 & 5.8 & 28.4 & 64.9 & 6.7 \\
\hline 1941 & 26.9 & 67.1 & 6.0 & 26.0 & 67.0 & 7.0 \\
\hline 1946 & 26.7 & 66.9 & 6.4 & 24.9 & 67.9 & 7.1 \\
\hline 1951 & 30.0 & 63.4 & 6.6 & 25.0 & 67.1 & 7.9 \\
\hline 1956 & 30.8 & 62.2 & 6.9 & 25.8 & 65.8 & 8.4 \\
\hline 1961 & 30.1 & 62.5 & 7.4 & 25.2 & 65.6 & 9.1 \\
\hline 1966 & 26.8 & 65.0 & 8.1 & 23.0 & 66.5 & 10.5 \\
\hline 1971 & 24.3 & 66.4 & 9.3 & 20.5 & 67.8 & 11.6 \\
\hline 1976 & 21.8 & 67.4 & 10.8 & 20.6 & 66.7 & 12.8 \\
\hline 1981 & 19.9 & 67.9 & 12.2 & 22.0 & 64.7 & 13.3 \\
\hline 1986 & 19.3 & 67.9 & 12.8 & 21.4 & 66.1 & 12.5 \\
\hline
\end{tabular}

Until 1906 the average age of the population appeared to be the same and hardly increased, while mortality had already decreased significantly in both countries. The reason was - as generally in the European demographic transition - high net reproduction. The phase in which the population in Hungary is, on the average, more aged than that in Finland began in 1911 and lasted until 1986. First, under the impact of the great absence of births in Hungary during World War I, a difference of $1-1.5$ years formed. During the Finnish baby-boom the difference grew to three years. From the 1970s on, the difference disappeard step by step. The reasons may have been, partly, the higher number of children and increasing mortality in Hungary and, partly, the significant decrease in mortality in Finland.

Population proportions by age groups show that within the average age the Hungarian age structure was older also when regarded in detail. The proportion of those aged 0-14 years was lower in Hungary from 1901 to 1975, on the average by 3 percentage points. The proportion of the working-age population was higher in Hungary from 1881 to 1971, with the exception of 1936 when the extraordinary smallnumber cohorts born during World War I had just entered this age group. The proportion of those aged 65 years and over was higher in Hungary, on the average by one percentage point, from 1926 to 1981 (Table 2).

These proportions formed specifically in a way that, nevertheless, made the dependency rate higher in Finland from the beginning essentially till the 1970s (Figure 9). In this the impact of the extremely low reproduction of the number of births in Hungary is also expressed.

The development of the dependency rate in the demographic transition deserves special attention. From Figure 9 it can be seen that the dependency rate fell from the initial value of $0.65-0.70$ to about 0.5 . Namely, the proportion of those aged $15-64$ years increased from the level of 0.6 to the proximity of 0.7 . 
How can it be explained? If by the end of the transition the NRR would have reached a level of about 1.0, the age structure of the actual population - disregarding some irregularities - would be near to the age structure of the stationary population calculated from the most recent life tables. Until the 1970 s, within the stationary population estimated for each five-year calendar period, the dependency rate was nearly constant and nearly at the same level in both countries (Figure 10). This level (around 0.53 ) could be characteristic also of the dependency rate within the actual population which is, however, lower than that. Evidently, this is connected with fertility having been established below replacement level. This can be interpreted also in a way that in both countries an sadditional reducing» in the number of children has appeared. The actual burden of support may have been too great or its distribution in too narrow a sphere. For example, when secondary education became widespread, those aged 15-19 years found themselves outside working age groups. In Hungary pensionable age begins at 60 years for men and 55 years for women which in turn, also significantly reduces the labor force.

The generalization of this way of thinking may lead to an actual intention to change (to increase) the proportion of the working age population. This could be done in four ways. The first has already been »tried out» by the population of both countries by reducing the number of children. The second has been winvented» by Hungary by increasing mortality. The proportion of those of working age could be increased by in-migration, for which in both countries - and because of its economic performance primarily in Finland - there might be some possibilities. Finally, the dependency rate can be reduced by »redefining» the age structure of the population, primarily by increasing the beginning of pensionable age.

All this seems to be all the more important because the established dependency rate is provisional and expected to change in the near future. In Finland, when the cohorts of the baby-boom enter old age a jump in the dependency rate is expected. Independently from this, the new mortality trends by themselves are operating towards a rise in the dependency rate (see the last three points on Figure 10).

Figure 9. Dependency rate of population in calendar years, Finland and Hungary, 1881-1986.

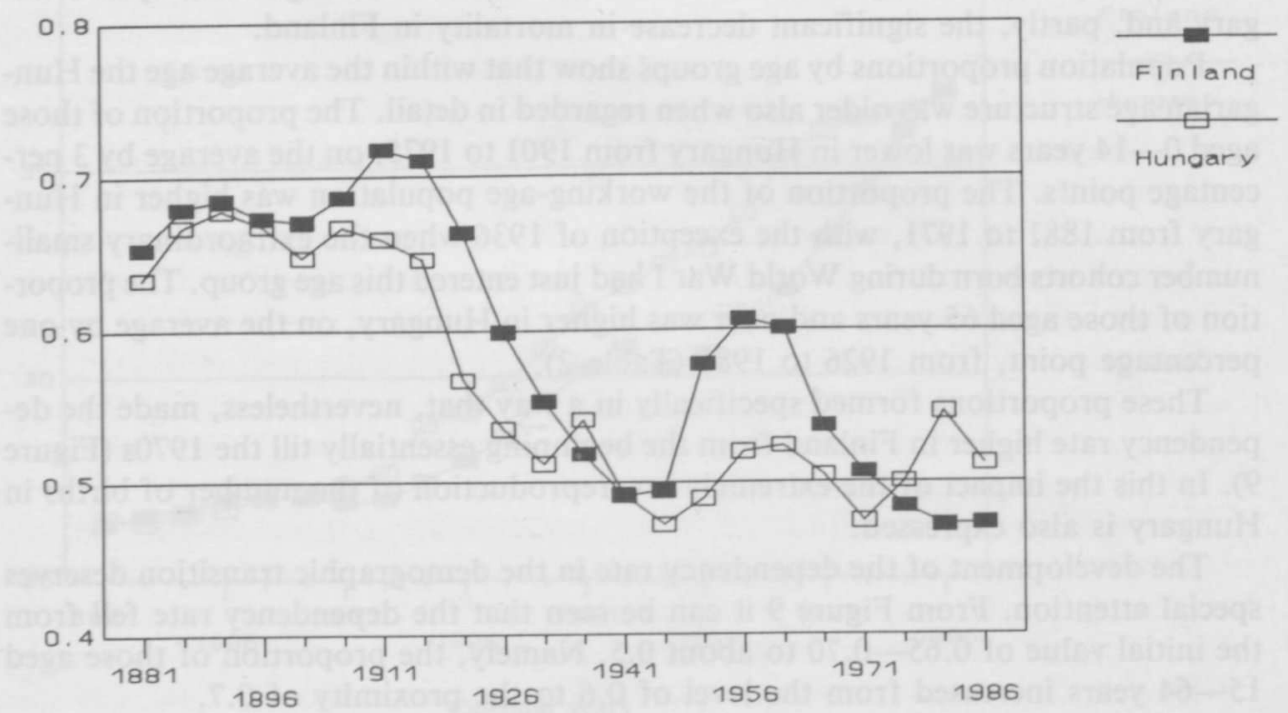

Calendar years 
Figure 10. Dependency rate of stationary population in calendar periods, Finland and Hungary, 1881-1985, in millions.

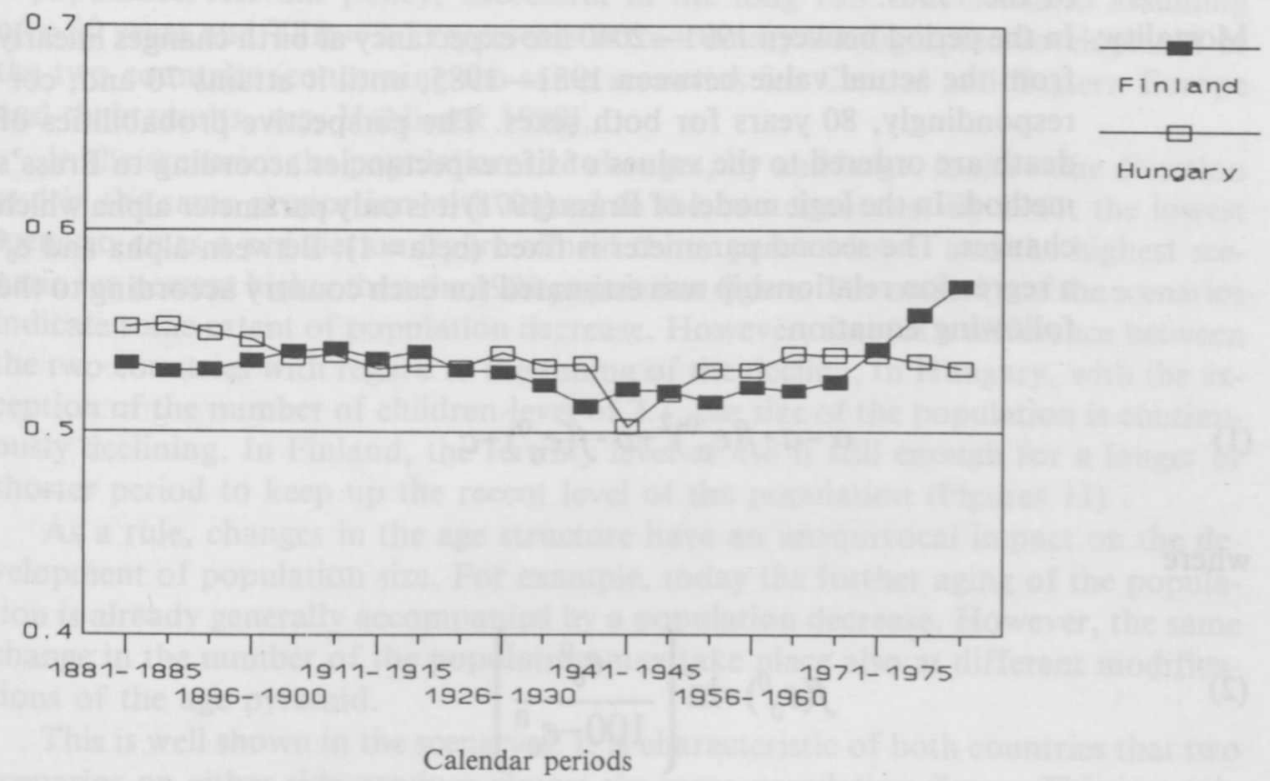

\section{Scenarios}

The established level of phenomena and especially the age structure of the population constitute an important factor modifying future changes. It has been known since Lotka that if the intensity of phenomena in two populations is identical, after a time the age structure of the two populations will become identical, too (see, Tekse 1975). Lopez has proved that the same process will be witnessed also in the case of identically changing mortality and fertility conditions (Lopez 1961). The population "attempts to forget» its original age structure. However, it needs a long time. In a shorter run the impact of the original (initial) age structure is very great (Valkovics 1989).

For the scenarios, the respective starting positions of the two countries showed similarities and differences, both of which seemed to be significant. With the TFR around 1.8, the respective fertility levels were similar. The respective average ages of the population were almost the same. Nor did the proportions of the main age groups show any great differences.

There was a difference regarding mortality level. Average life expectancy at birth was 5 years longer in Finland. The states of the age structure, as compared to the stationary population, were different in the two countries. Average stationary age, i.e. half of average life expectancy at birth was 0.3 years longer in Finland and 2.3 years shorter in Hungary than the average age of the actual population. Thus, in the Finnish age structure there were still some reserves of growth while in Hungary the age pyramid was also »operating» towards a decrease in population size.

By combining two mortality and three fertility assumptions six »not impossible» population scenarios (Lutz et a., 1988) were prepared for both countries. The calculation of the scenarios was performed by the cohort component method, for fiveyear age groups and for five-year calendar periods. International migration is not included in the projections. The assumptions are the following: 
Fertility: Between 1991-2040 TFR is constant on the levels of values $1.5,1.8$ and 2.1 , the timing of fertility is the same as that measurable in the first half of the 1980s.

Mortality: In the period between 1991-2040 life expectancy at birth changes linearly from the actual value between 1981-1985, until it attains 70 and, correspondingly, 80 years for both sexes. The perspective probabilities of death are ordered to the values of life expectancies according to Brass's method. In the logit model of Brass (1971) it is only parameter alpha which changes. The second parameter is fixed (beta $=1)$. Between alpha and $\mathrm{e}_{0}{ }^{0}$ a regression relationship was estimated for each country according to the following equation:

$$
\alpha=a \cdot f\left(e_{0}\right)^{2}+b \cdot f\left(e_{0}^{g}\right)+c
$$

where

$$
f\left(e_{0}{ }^{0}\right)=\ln \left(\frac{e_{0}^{0}}{100-e_{0}^{0}}\right)
$$

The values of alpha are $-2.5,-2.0, \ldots,+2.0,+2.5$. The standard life table is that of $1981-1985 . \mathrm{e}_{0}{ }^{0}$ is the life expectancy at birth of the life table calculated by the logit model using a value of alpha and the fixed beta.

Table 3. Regression parameters for Equation (1), estimated by the method of least-squares

$\begin{array}{lccc}\text { Country } & a & b & c \\ \text { Finland } & -0.13 & 0.74 & 0.86 \\ \text { Hungary } & -0.15 & 0.83 & 0.68\end{array}$

With Equation (1) from estimated parameters a, b, c and from a given value $e_{0}{ }^{0}$ it was possible to calculate the parameter alpha. Taking the life table between 1981 -1985 as a standard and using Brass's formula with alpha calculated and beta $=1$, a new life table was estimated in which average life expectancy at birth is approximately identical with the value $\mathrm{e}_{0}{ }^{0}$ given in advance.

From among the mortality assumptions, $\mathrm{e}_{0}{ }^{0}=70$ years in Hungary continues the level established by the 1960 s and which has been stagnating ever since. With regard to Finland this means an increase in the intensity of mortality. Matching this with an 1.5 TFR value actually leads to a catastrophe scenario for both countries. TFR $=1.8$ projects ahead the established average number of children in the 1980s. The level 2.1 would be tantamount to a baby-boom.

The $\mathrm{e}_{0}{ }^{0}=80$ years in Finland corresponds to the long-term mortality trend. In Hungary, this would mean the replacement of the present-day formula by a continuous and dynamic decrease. When this is matched with TFR $=1.5$, the scenario would 
mean a second demographic transition like that present in Western Europe since the mid-1970s (van de Kaa 1987). Of higher fertility levels, TFR $=1.8$ would suppose a population-relevant policy, successful in the long run. The scenario assuming $\mathrm{e}_{0}{ }^{0}=80$ years and TFR $=2.1$ represents extraordinary demographic development of the two countries (concerning the same scenarios for Central and Eastern Europe and their results, see, Hablicsek 1990).

In the scenarios the population size changes, by and large, in the same direction and in the same proportion with regard to the two countries. By 2041, the lowest scenario gives a population figure almost thirty percent lower and the highest scenario ten percent higher than the 1986 population figure. The majority of the scenarios indicate some extent of population decrease. However, there is a difference between the two countries with regard to the timing of the decline. In Hungary, with the exception of the number of children-level of 2.1 , the size of the population is continuously declining. In Finland, the fertility level of 1.8 is still enough for a longer or shorter period to keep up the recent level of the population (Figures 11).

As a rule, changes in the age structure have an unequivocal impact on the development of population size. For example, today the further aging of the population is already generally accompanied by a population decrease. However, the same change in the number of the population may take place also at different modifications of the age pyramid.

This is well shown in the scenarios. It is characteristic of both countries that two scenarios on either side produce almost the same population figure. This is a rule between the number of children and the mortality level, on the one hand, and population size on the other. To add ten years to the life span or to increase the average number of children by 0.3 leads to identical changes in population size. However, the development of the age structure will be significantly different.

Let us take two scenarios as examples. Provided $\mathrm{e}_{0}{ }^{0}=70$ years and TFR $=2.1$ the size of the population in 2041 is 4.9 million in Finland and 10.2 million in Hungary. The proportion of those aged $0-14$ years is 21 percent for both countries. Provided $\mathrm{e}_{0}{ }^{0}=80$ years and TFR $=1.8$ the population figures ( 4.8 and 10.1 million, respectively) almost coincide with those previously mentioned. However, the proportion of those aged $0-14$ years is lower (17 and 19 percent, respectively).

On this basis, scenarios could be prepared in which - phasing in time - preference is given intermittently first to the number of children and next to mortality and vice versa. Thus, one could arrive at calculations in which a constant number of the population would be established by an age structure changing dynamically, i.e. in a wave-like manner. With such scenarios it would be possible to present the impact of two-generation waves as it would follow from Easterlin's or Grauman's mechanism (Keyfitz 1982).

The age structure continues to get older in almost every scenario. Because of earlier fluctuations in the number of births, significant waving is expected in the changes in the population proportions by age groups. The maximum and minimum places of the waves will be at different points of time regarding the two countries. Nevertheless, the proportions of the main age groups in 2041 are essentially the same for both countries in every scenario (ergodicity).

If the fertility level is below 2.1, the proportion of those aged $0-14$ years will decline. If the number of children does not even reach the value of 1.5 , the above proportion will fall from the present-day 20 percent to lower than 15 percent. In the case of a level of 1.8, which seems to be more realistic, the proportion of the young will decrease, depending on the improvement in mortality, to $16-18$ percent (Figures 12). 
Figure 11. Size of the population in different scenarios, 1991-2041.

Finland (in thousands)
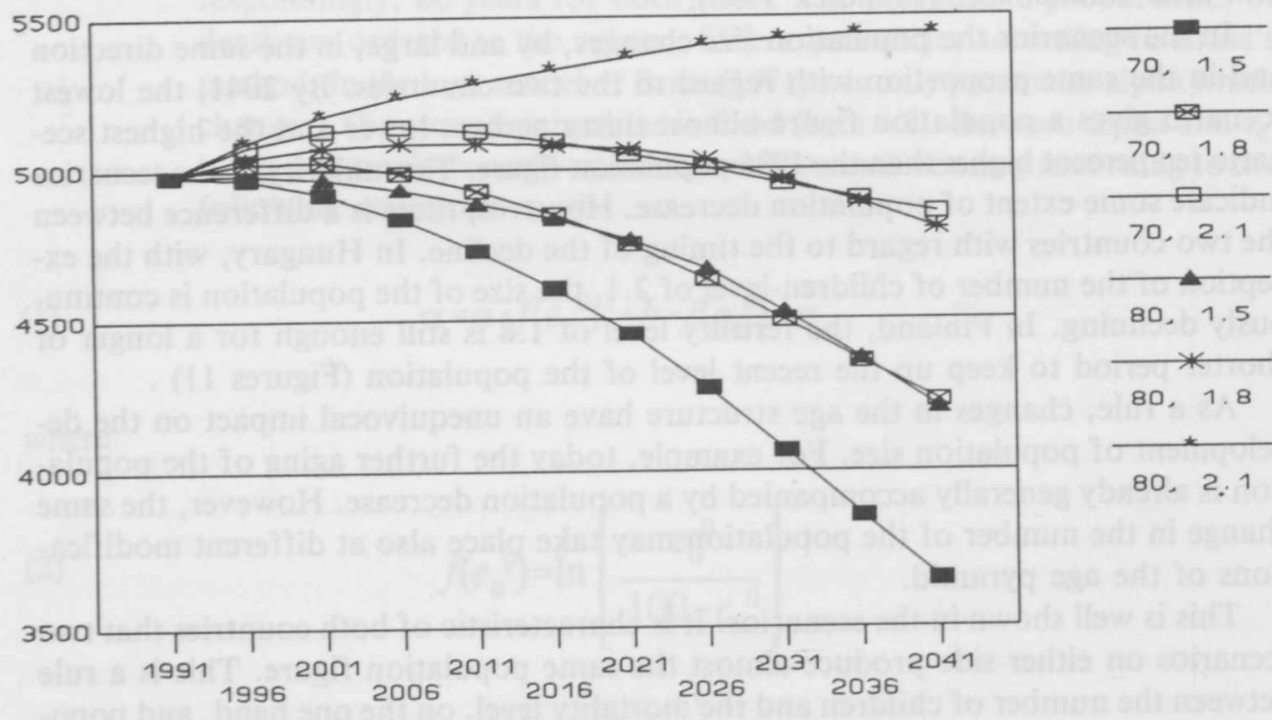

Calendar years

Hungary (in millions)
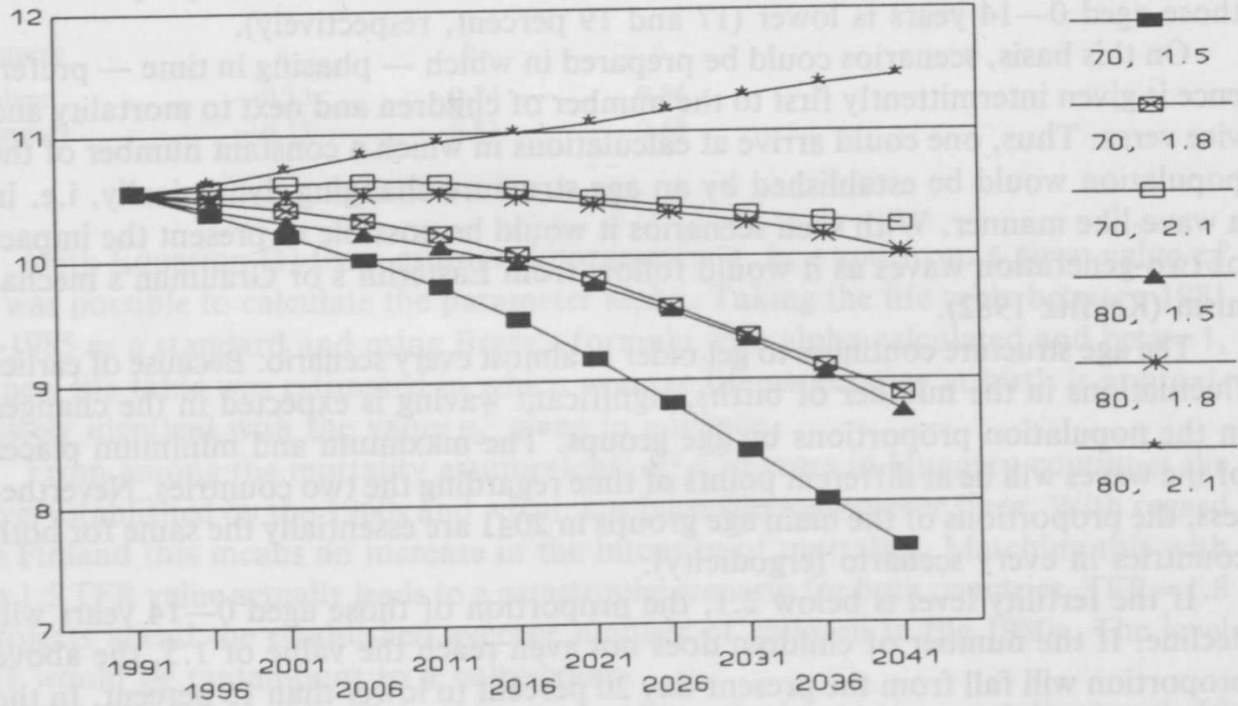

Calendar years 
Figure 12. Rate of 0-14-year-old population in different scenarios, 1991-2041.

Finland (in percentage)
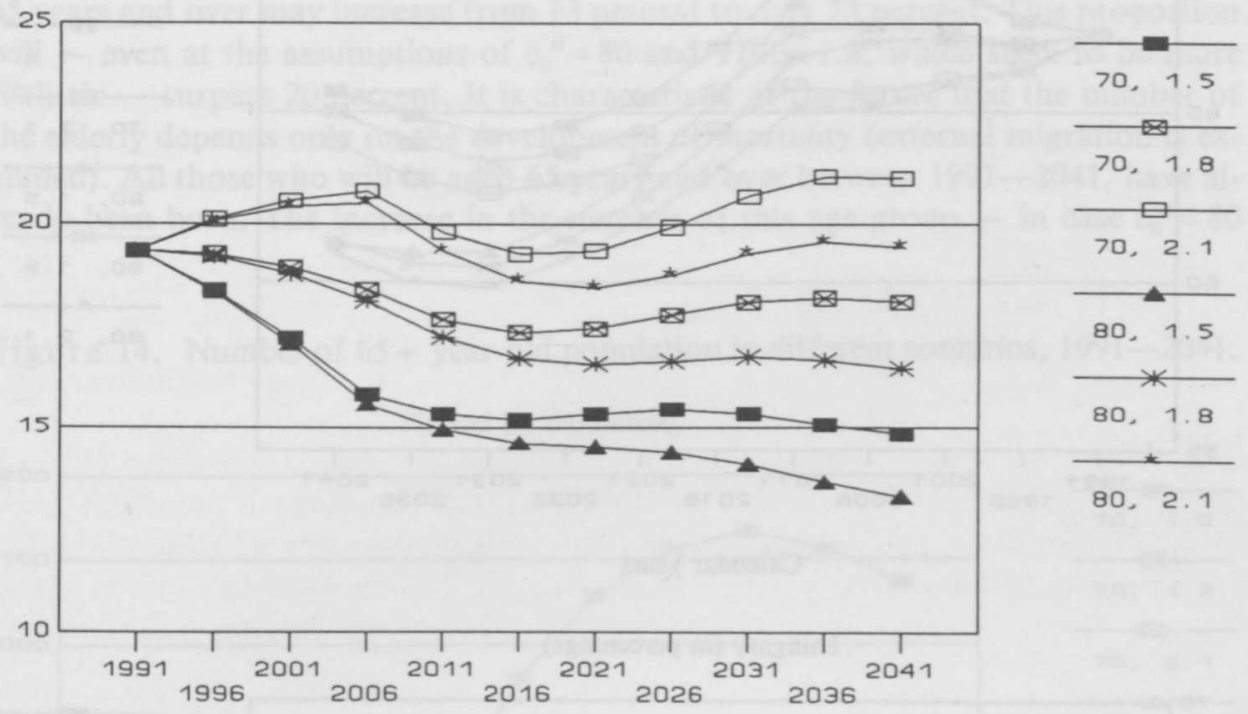

Calendar years

Hungary (in percentage)
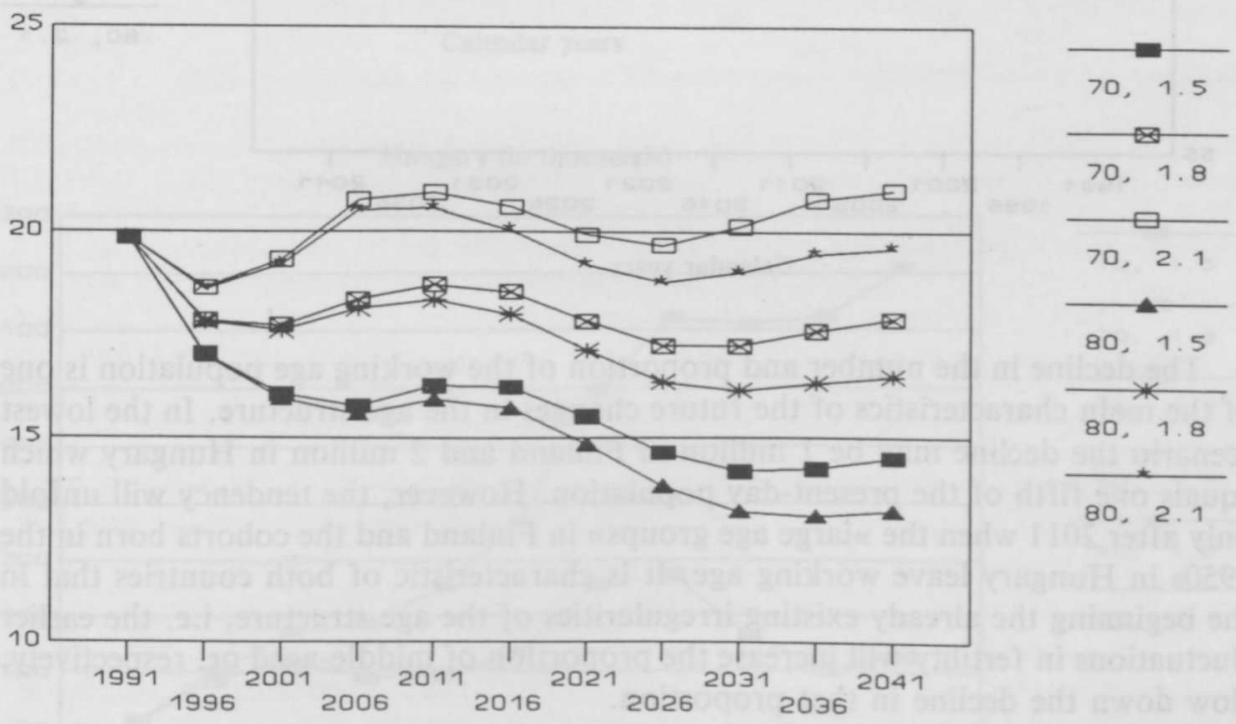

Calendar years 
Figure 13. Rate of 15-64-year-old population in different scenarios, 1991-2041.

Finland (in percentage)
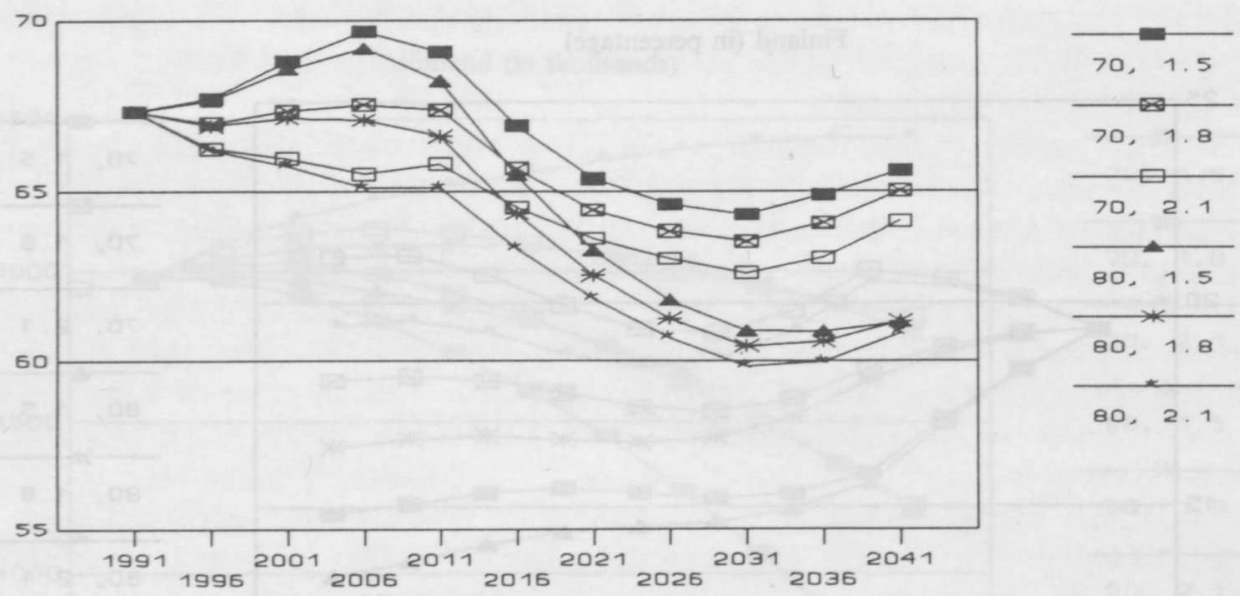

Calendar years

Hungary (in percentage)
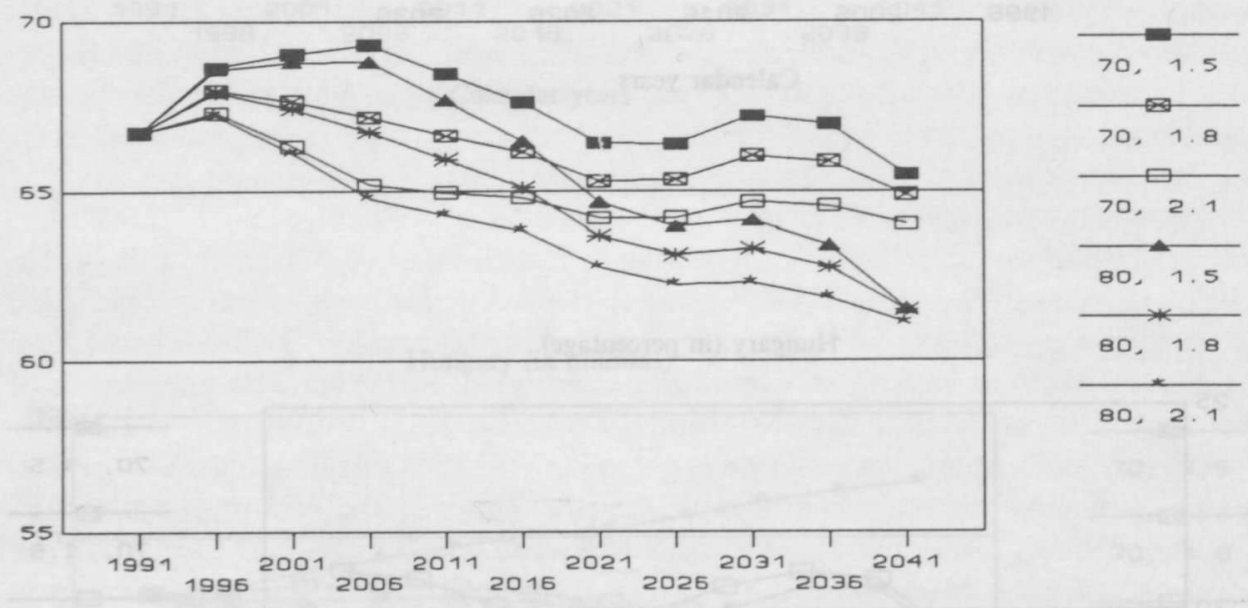

Calendar years

The decline in the number and proportion of the working age population is one of the main characteristics of the future changes in the age structure. In the lowest scenario the decline may be 1 million in Finland and 2 million in Hungary which equals one-fifth of the present-day population. However, the tendency will unfold only after 2011 when the »large age groups» in Finland and the cohorts born in the 1950 s in Hungary leave working age. It is characteristic of both countries that in the beginning the already existing irregularities of the age structure, i.e. the earlier fluctuations in fertility will increase the proportion of middle-aged or, respectively, slow down the decline in that proportion.

The impact of different mortality levels will have its breakthrough later. The proportions will converge in a focal point depending on the mortality level. Life expectancy at birth, which will be ten years longer, will reduce the proportion of those 
aged 15-64 years from 65 to 60 percent. This is one of the consequences of postindustrial mortality (Figures 13).

The other consequence is that at least the above 5-percent decrease - this depends on the level of the number of children - is added to the proportion of the elderly. In the lowest scenario $\left(\mathrm{e}_{0}{ }^{0}=70\right.$ and TFR $\left.=1.5\right)$ the proportion of those aged 65 years and over may increase from 13 percent to over 25 percent. This proportion will - even at the assumptions of $\mathrm{e}_{0}{ }^{0}=80$ and TFR $=1.8$, which seem to be more realistic - surpass 20 percent. It is characteristic of the future that the number of the elderly depends only on the development of mortality (external migration is excluded). All those who will be aged 65 years and over between 1991-2041, have already been born. The increase in the number of this age group - in case $e_{0}{ }^{0}=80$

Figure 14. Number of $65+$ year-old population in different scenarios, 1991-2041.

Finland (in thousands)
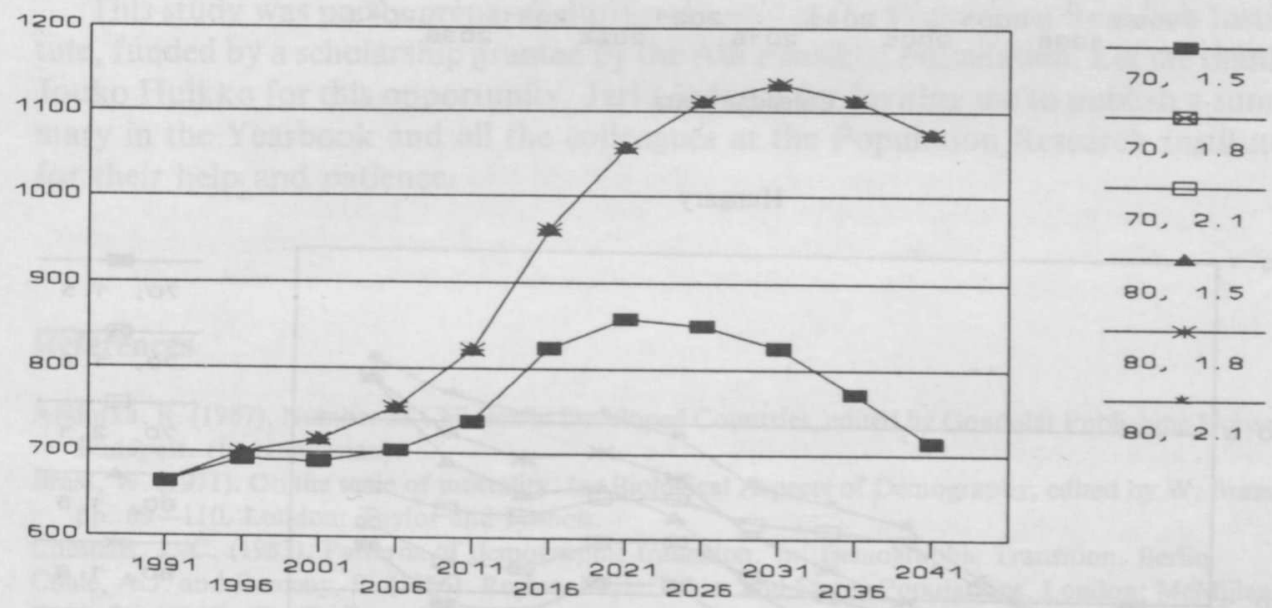

Calendar years

Hungary (in thousands)
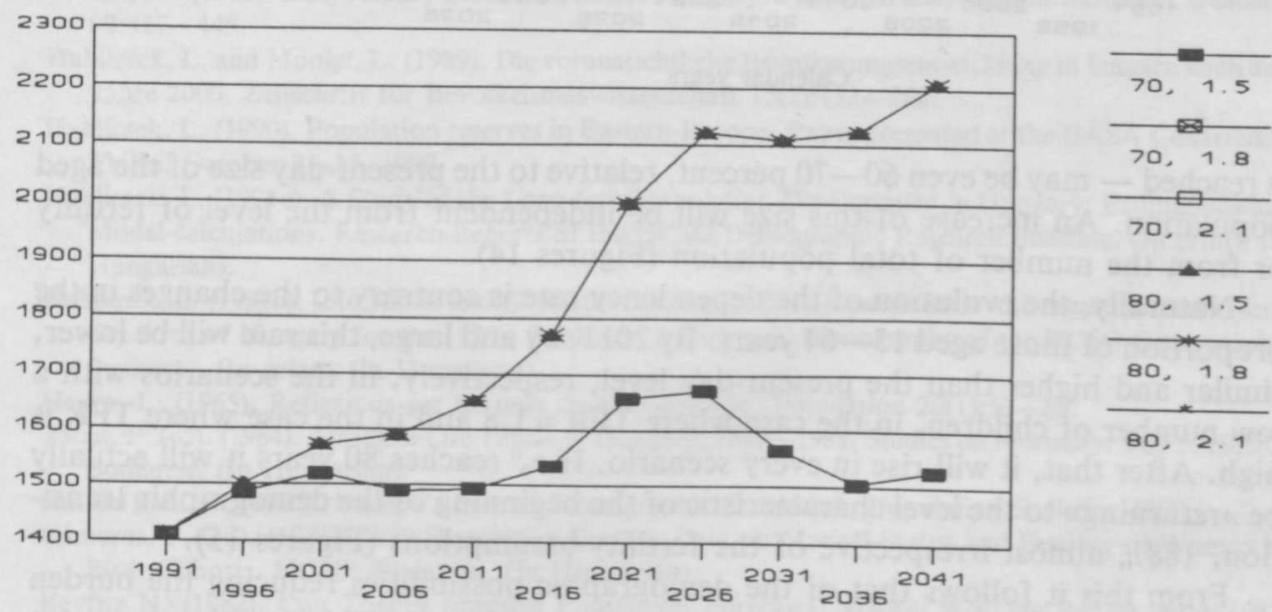

Calendar years 
Figure 15. Rate of dependency in different scenarios, 1991-2041.

Finland
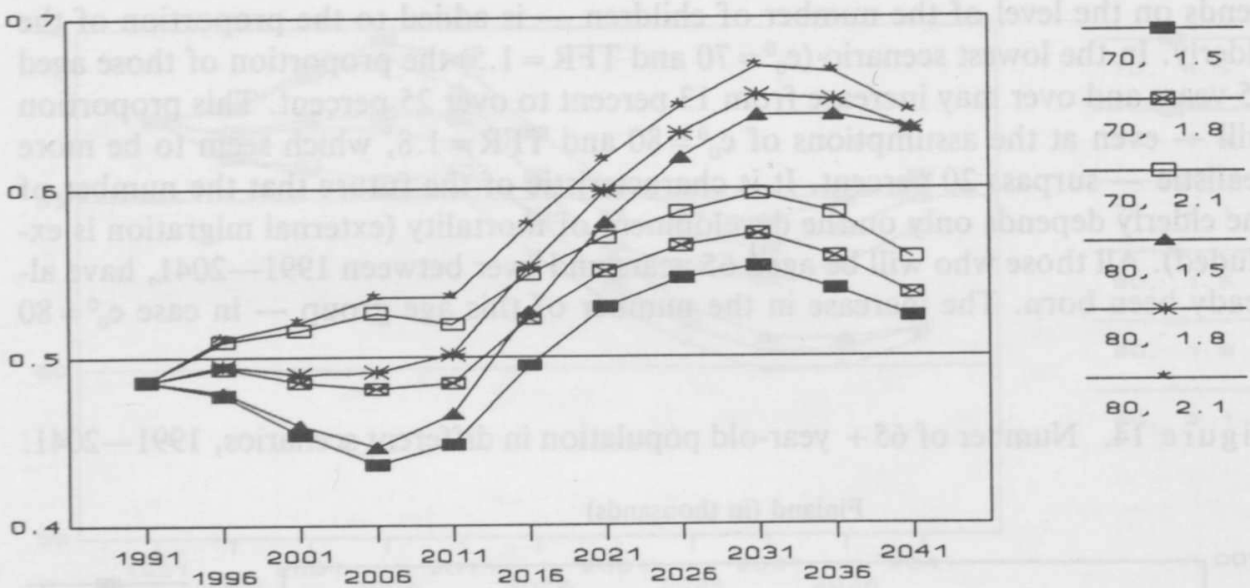

Calendar years

Hungary
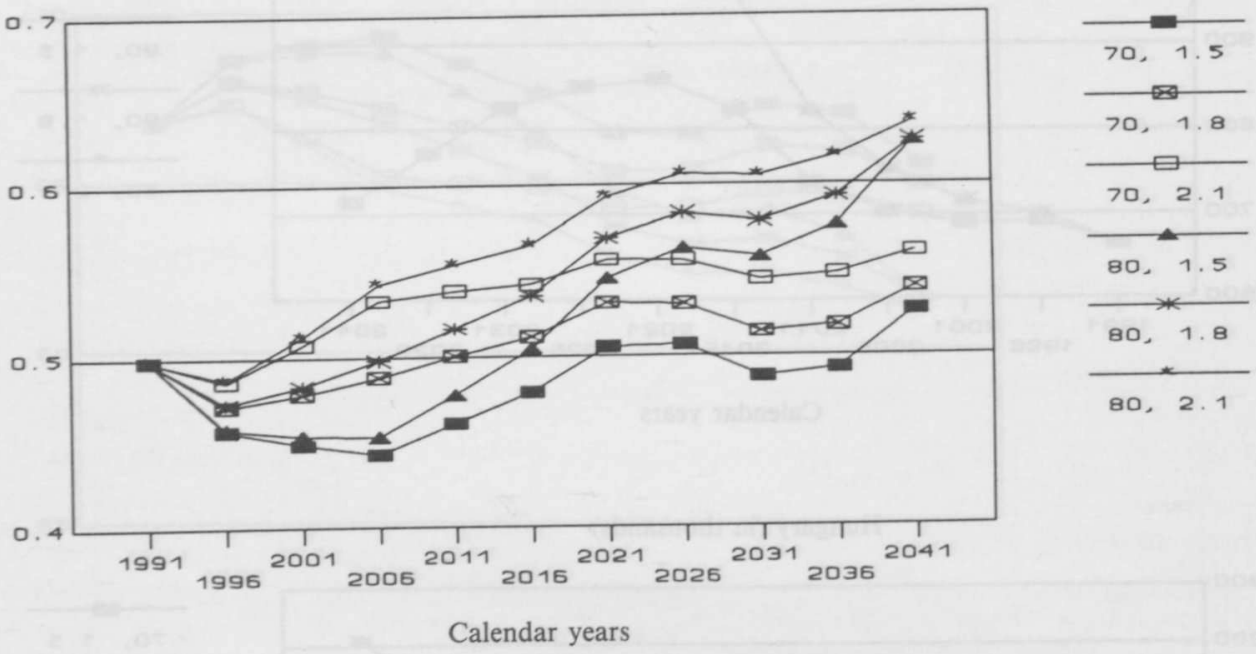

is reached - may be even 60-70 percent, relative to the present-day size of the aged population. An increase of this size will be independent from the level of fertility or from the number of total population (Figures 14).

Naturally, the evolution of the dependency rate is contrary to the changes in the proportion of those aged 15-64 years. By 2011, by and large, this rate will be lower, similar and higher than the present-day level, respectively, in the scenarios with a low number of children, in the case where TFR $=1.8$ and in the case where TFR is high. After that, it will rise in every scenario. If $\mathrm{e}_{0}{ }^{0}$ reaches 80 years it will actually be wreturning» to the level characteristic of the beginning of the demographic transition, 1881, almost irrespective of the fertility assumptions (Figures 15).

From this it follows that of the demographic possibilities reducing the burden of support society has a further reducing in the number of children will not prevent 
a long-term increase in the dependency rate. The mortality stagnation should be excluded, too. The impact of forced in-migration may be such that the number of the elderly will jump up later. It seems that in both countries (in Hungary the sooner the better) it would be necessary to advance the idea of concluding a new »social contract». The essence would be the extension of the duration of the active phase of life toward old age. The financial means thus liberated could be used to increase the funds from which newborns receive advances until they reach adulthood. One of the ways to approach the population optimum (Coale 1972, pp. 49-51) also shows that for higher reproduction a younger average age for income distribution is needed.

\section{Acknowledgements}

This study was partly prepared during my stay at the Population Research Institute, funded by a scholarship granted by the Alli Paasikivi Foundation. Let me thank Jouko Hulkko for this opportunity, Jarl Lindgren for inviting me to publish a summary in the Yearbook and all the colleagues at the Population Research Institute for their help and patience.

\section{References}

Andorka, R. (1987). Number of Children in Developed Countries, edited by Gondolat Publishing House. Budapest. (In Hungarian).

Brass, W. (1971). On the scale of mortality. In: Biological Aspects of Demography, edited by W. Brass, pp. 69-110. London: Taylor and Francis.

Chesnais, J.-C. (1983). Patterns of demographic transition. In: Demographic Transition. Berlin.

Coale, A.J. and Demeny, P. (1966). Regional Life Tables and Stable Populations. London: McMillan.

Coale, A. (1969). The Decline of Fertility in Europe from the French Revolution to World War II. Ann Arbor.

Coale, A.J. (1972). The Growth and Structure of Human Populations. A Mathematical Investigation. Princeton.

CSO (1987). Population in Finland. Past, Present, Future. Helsinki: Central Statistical Office of Finland.

Demeny, P. (1968). Early fertility decline in Austria-Hungary: a lesson in demographic transition. Daedalus 97:427-445.

Hablicsek, L. and Monigl, L. (1989). Die voraussichtliche Bevolkerungsentwicklung in Ungarn nach dem Jahre 2000. Zeitschrift fur Bevölkerungswissenschaft 15(2):133-162.

Hablicsek, L. (1990). Population reserves in Eastern-Europe. Paper presented at the IIASA Conference, Tbilisi, October 7-13, 1990.

Hablicsek, L. (1991a). A Study of the Long-term Population Development in Hungary: Estimations and Model-calculations. Research Reports of the HCSO Demographic Research Institute. (In print). (In Hungarian).

Hablicsek, L. (1991b). Life Tables and Estimation of Population Characteristics with regard to the Presentday Area of Hungary for the 1820 s. Booklets of Historical Demography of the HCSO Demographic Institute). (In print). (In Hungarian).

Henry, L. (1965). Reflexions sur les taux de reproduction. Population 20(1):53-69.

Józan, P. (ed). (1984). Abridged Life Tables of Hungary, 1949-1981. Studies on Mortality. Vol. 5. HCSO. Budapest. (In Hungarian).

van de Kaa, D. (1987). Europe's Second Demographic Transition. Population Bulletin. 42(1).

Kámaras, F. (ed). (1981). 1970 Population Census. Data on Marital Status and Fertility of Women by Birth Cohorts. HCSO. Budapest. (In Hungarian).

Keyfitz N. (1982). Can Theory Improve Population Forecasts? IIASA Working Papers, May 1982. WP-82-39. 
Klinger, A. (1980). The fertility rates in the counties during the last 150 years. Statistical Review 58(1): $74-85$.

Kolari, R. (1980). Kohorttikuolleisuus Suomessa v:sta 1851 lähtien. (Cohort mortality in Finland from 1851). Studies No. 57. Helsinki: Central Statistical Office of Finland.

Lindgren, J. (1990). Towards and Aging Society. Some Demographic and Socioeconomic Aspects of Population Aging in Finland. Publications of the Population Research Institute. Series D, No. 25. Helsinki.

Lopez, A. (1961). Problems in Stable Population Theory. IX. Princeton: Office of Population Research, Princeton University.

Lotka, A.J. (1907). Relation between birth rates and death rates. Science 26:21-22.

Lutz, W. (1987). Finnish Fertility since 1722. Publications of the Population Research Institute. Series D, No. 18 .

Pallós, E. (1972). Life Tables of Hungary from 1900/01 to 1967/68. Publications of the HCSO Demographic Research Institute, No. 34, 1972/2. (In Hungarian).

Preston, S. (ed.)(1978). The effect of infant and child mortality on fertility, pp. 1-18. Academic Press.

Schwarz, K. (1986). Die Kohorten- oder Laengsschnittanalyse in der amtlichen Bevölkerungsstatistik des Deutschen Reichs und der Bundesrepublik Deutschland. Zeitschrift für Bevölkerungswissenschaften 12(3):325-345.

Tekse, K. Introduction to the Stable Population Theory. Budapest: Statistical Publishing House. (In Hungarian).

Valkonen, T. (1984). Evolution of life expectancy and population age structure in Finland. In: Proceedings of the First Finnish-Soviet Seminar on Demography. Publications of the Finnish Demographic Society, No. 8, pp. 56-74. Helsinki.

Valkovics, E. (1981). On Some Practical Difficulties of the Analysis of the Demographic Transition. Research Reports of the HCSO Demographic Research Insitute, 1982/5. (In Hungarian).

Valkovics, E. (1989). Population ageing in perspective: past and future trends. International Population Conference, Prague, Czechoslovakia, July 3-7, 1989. (Unpublished paper).

Wolf, D., Wils, B., Lutz, W. and Scherbov, S. (1988). Population Futures for Europe: an Analysis of Alternative Scenarios to the Year 2050. IIASA Conference, Sopron, Hungary, October 18-21. (Lutz et al 1988). 